\title{
Characterization of the limestone blocks of Djabel estah in the region of Gafsa at the southwest of Tunisia
}

\begin{abstract}
The gradual increase in the energy cost of some building materials and insulation requires a return to the use of local natural materials. Among the most abundant materials construction are the limestone blocks. In this context, a broad experimental companion was conducted to provide more data on limestone blocks derived from Djabal Estah in the region of Gafsa at the southwestern of Tunisia. The experimental program includes physical, mechanical and chemical tests on blocks limestone. Thereafter, an atomic absorption spectrometer "AAS" was used to determine the chemical composition of the limestone. The experimental results on the limestone blocks showed they can be used as building materials. By cons, low wear resistance and impact prohibit the use of limestone aggregates in the implementation of pavements.
\end{abstract}

Keywords: local natural materials, limestone block, characterization, atomic absorption spectrometer, chemical analysis
Volume 3 Issue 2 - 2017

\author{
Malek Jedidi, ${ }^{1,2}$ Omranne Benjeddou ${ }^{1,2}$ \\ 'Department of Civil Engineering, Higher Institute of \\ Technological Studies of Sfax, Tunisia \\ ${ }^{2}$ Civil Engineering Laboratory, University of Tunis El Manar, \\ Tunisia
}

Correspondence: Malek Jedidi, Higher Institute of Technological Studies of Sfax, Department of Civil Engineering, B.P.88, 3099 Sfax, Tunisia, Tel 21698258681 ,

Email malekjedidi@yahoo.fr

Received: June 03, 2017 | Published: July 29, 2017
Abbreviations: $\mathrm{M}$, dry mass of the sample; $\mathrm{MH}$, wet mass of the sample; VS, volume of voids; Vpar, volume of the paraffinized sample; $\mathrm{M}$, mass of elements lower than $1.6 \mathrm{~mm}$; $\mathrm{Ab}$, water absorption coefficient \%; MDE, micro-deval coefficient; AAS, atomic absorption spectrometer

\section{Introduction}

The sectors of building materials, construction and public works are considered an economic and social engine for Tunisia. They largely contribute to improving the country's infrastructure and the absorption of a large mass of labor. ${ }^{1}$ However, the development of these sectors depends on the qualitative and quantitative availability of useful substances in the various regions. In Tunisia, the study of useful substances has become an absolute necessity. Indeed it is considered firstly as a guide to the regional potential into useful materials and also as background material for the launch of new projects. The study of useful substances is a determining factor for sustainable development. The present work aims to contribute to the development of sites of useful substances in the governorate of Gafsa in order to identify their areas of use in the industry.

Since these substances have now become industrial products, economically profitable and since the exploitation of these substances is also a source of employment, it is therefore part of the country's economic development. Among these most abundant substances are the limestone blocks and their deposits. Limestone is formed mainly by the consolidation of sediments deposited in the seabed sediments coming from the precipitation of carbonates by biological processes or physical-chemical phenomena occurring in the seabed. ${ }^{2}$ The limestone contains between 60 and $100 \%$ calcium carbonate $\mathrm{CaCO}_{3} \cdot{ }^{3}$ Other materials can be found there, such as magnesium carbonate $\mathrm{MgCO}_{3}$ and quartz $\mathrm{SiO}_{2}{ }^{4}$ It is in this context that this work has been elaborated and which is interested in the physicochemical characterization of the limestone blocks extracted from Djabel Estah in the region of Gafsa at the South West of Tunisia. Indeed, samples were studied using the following tests: density, bulk density, water absorption coefficient, Micro-Deval, pH-meter and the chemical analysis made with the apparatus "AAS “. Similarly, samples of masonry stone, Tozeur brick and ordinary brick were tested.

\section{Experimental study}

\section{Geological description of the site}

The Governorate of Gafsa is located in the south-west of Tunisia at about $355 \mathrm{Km}$ from the capital. It is surrounded by five governorates: the governorate of Kabila, to the south; the governorate of Tozeur, in the South-East; the governorate of Gibes in the south-west; the governorate of Sidi Bouzid, in the Northeast; and the governorate of Kasserine in the northwest Figure 1. The Governorate of Gafsa is located in the southern sector of the Saharan Atlas in the southwest of Tunisia, between the high steppes and the Sahara and enjoys a specific geographical location. Indeed, the region is a zone of passage between the countries of the Arab Maghreb (Libya and Algeria) and the African countries through the Saharan road. The site of Djabel Estah is located in the West of the city of Gafsa at about $30 \mathrm{Km}$. It is a massive whitish chalky limestone in metric benches Figure 2. It is the upper limb of the Breda formation of lower Maastricht Ian age, this term constitutes a morphological marker. ${ }^{1}$ 


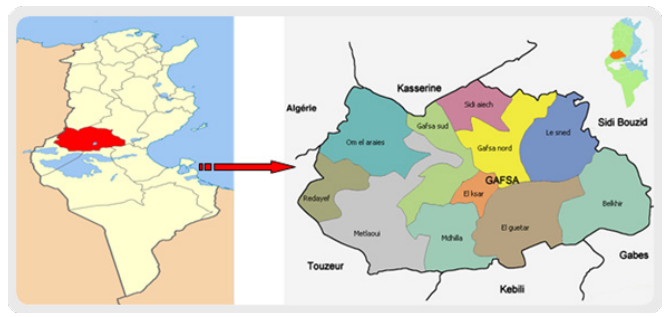

Figure I Geographical location of Gafsa Governorate.

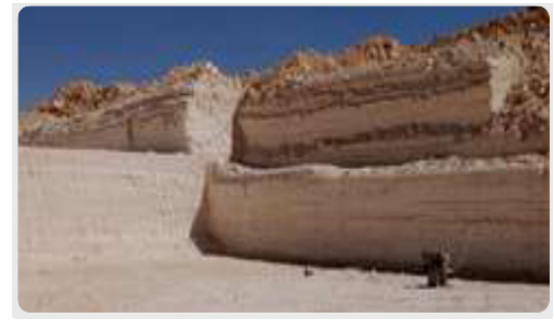

Figure 2 Detail view of the carbonates of Djabel Estah.

\section{Used materials}

A series of tests were carried out on limestone blocks extracted from Djabel Estah in the region of Gafsa at the southwest of Tunisia Figure 3.

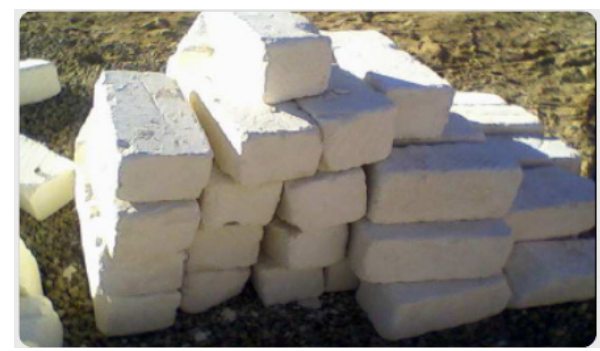

Figure 3 The limestone blocks of Djabel Estah.

\section{Materials and methods}

\section{Density}

The density is defined as the mass of the volume unit of the material "M" which constitutes the material, without taking into account the volume of voids " $\mathrm{V}$ ". It was determined according to the standard NF EN $1097-6^{5}$ by the following equation:

$$
M V R=M V 2-V 1(\mathrm{Kg} / \mathrm{m3})
$$

Where $\mathrm{M}$ is the dry mass of the sample in $\mathrm{Kg}$ and $\left(\mathrm{V}_{2}-\mathrm{V}_{1}\right)$ is the difference in volume in the graduated cylinder in $\mathrm{m}^{3}$

\section{Bulk density}

The bulk density is defined as the mass of the unit of volume of the material "M" constituted by the material and the voids it contains. It was determined according to the standard NF EN $1097-6^{5}$ by the following equation:

$$
M V A=M V-\operatorname{Vpar}(\mathrm{Kg} / \mathrm{m3})
$$

Where $\mathrm{M}$ is the dry mass of the sample in $\mathrm{Kg}$ and Vpar is the volume of the paraffin zed sample in $\mathrm{m}^{3}$

\section{Water absorption coefficient}

The water absorption coefficient is defined as the ratio of the increase in the mass of the sample after imbibition in water Figure $4 \& 5$, to the dry mass of the sample. It was determined according to the standard NF EN 1097- $6{ }^{5}$ by the following equation:

$$
A b=M H-M S M S x 100(\%)
$$

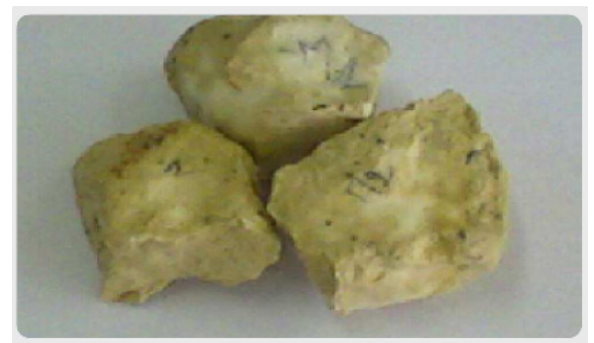

Figure 4 Samples of paraffin limestone blocks.

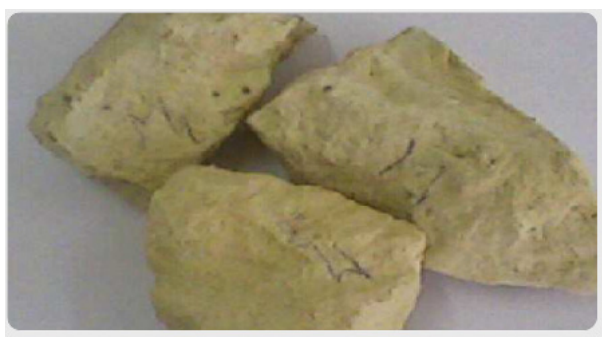

Figure 5 Samples of limestone blocks imbibed in water.

Where MH is the wet mass of the sample in Kg and MS is the dry mass of the sample in $\mathrm{Kg}$

\section{Micro-Deval}

Micro-Deval testing machine was used to determine the resistance of aggregates by abrasion Figure 6 . The machine consists of a steel frame, two stainless steel cylinders, $25 \mathrm{Kg}$ of $10 \mathrm{~mm}$ diameter stainless steel spheres and an automatic digital counter which allows the machine to stop automatically at the preset number of revolutions. The Micro-Deval coefficient was determined according to the standard NF EN $1097-1{ }^{6}$ by the following equation:
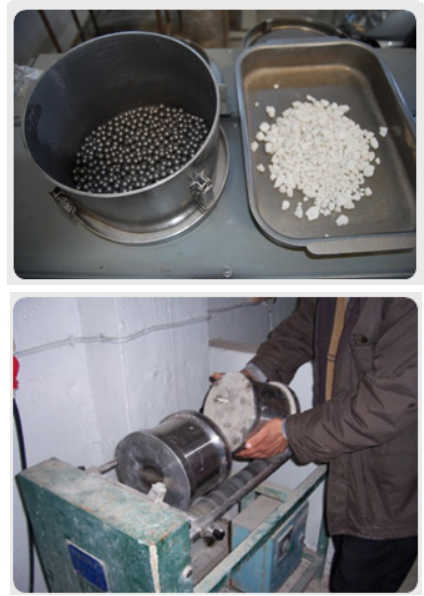

Figure 6 Micro-Deval test. 


$$
M D E=m M x 100(\%)
$$

Where $\mathrm{M}$ is the mass of the sample in $\mathrm{Kg}$ and $\mathrm{m}$ is the mass of elements lower than $1.6 \mathrm{~mm}$ in $\mathrm{Kg}$.

\section{Chemical analysis}

The test consists in identifying and quantifying the composition of a material sample with an atomic absorption spectrometry (AAS) Figure 7 which can be used to determine over 70 different elements in solution or directly in solid samples. ${ }^{7,8}$ The chemical analysis is carried out according to the standard NF EN $15586 .{ }^{\circ}$

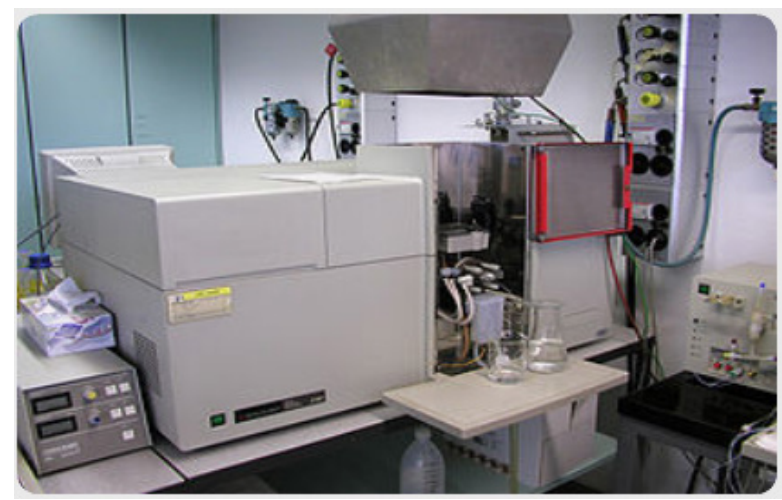

Figure 7 Atomic absorption spectrometry test.

\section{Results and discussion}

\section{Density}

Table 1 reports the values of the density of the limestone extracted from Djabel Estah as well as the values of the other building materials. The density values were calculated using equation 1 . It is found that the density of the limestone of the Djabel Estah is very close to those of the other materials, which shows that the limestone extracted from Djabel Estah can be used as building material provided satisfy the other tests: bulk density, water absorption coefficient and MicroDeval.

Table I Density of building materials

\begin{tabular}{ll}
\hline Materials & Density $\left(\mathrm{Kg} / \mathrm{m}^{3}\right)$ \\
\hline Limestone of Djabel Estah & 2373 \\
Construction limestone & 2046 \\
Brick of Tozeur & 2466 \\
Normal Brick & 2644 \\
\hline
\end{tabular}

\section{Bulk density}

Table 2 gives the values of the bulk density of the limestone extracted from Djabel Estah as well as the values of the other building materials. The bulk density values were calculated using equation 1. It is noted that the bulk density of the limestone of the Djabel Estah is very close to those of the other materials, which shows that the limestone extracted from Djabel Estah can be used as building material provided satisfy the other tests.
Table 2 Bulk density of building materials

\begin{tabular}{ll}
\hline Materials & Density $\left(\mathbf{K g} / \mathbf{m}^{3}\right)$ \\
\hline Limestone of Djabel Estah & 2043 \\
Construction limestone & 2059 \\
Brick of Tozeur & 2130 \\
Normal Brick & 2130
\end{tabular}

\section{Water absorption coefficient}

Figure 8 illustrates the values of the Water absorption coefficient of the limestone extracted from Djabel Estah as well as the values of the other building materials. The Water absorption coefficient values were calculated using equation 3. For aggregates used in concretes, the water absorption coefficient must not be greater than 5.5\%. By examining these results, it is found that the limestone of Djabel Estah cannot be used for the realization of a concrete since the values exceed considerably the average. Similarly, for the calcareous material, the water absorption coefficient is equal to $14 \%$ therefore it should not be used in concrete because of the risks of cracking. For the walls constructed by these limestone blocks, it is advisable to use special plasters (Plasters based on gypsum materials) to avoid any risk of cracking of the body of the coating which originates in the absorption of the water of mixing by the blocks of limestone.

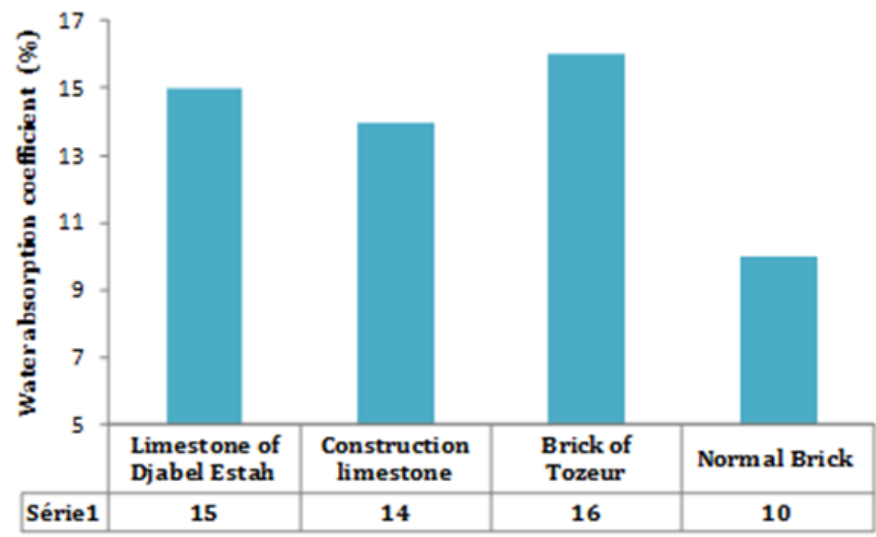

Figure 8 Water absorption coefficient of building materials.

\section{Micro-Deval}

Table 3 gives the values of Micro-Deval of the limestone extracted from Djabel Estah calculated using equation 4. From the results of the test, it can be seen that this limestone block has a very low wear resistance $(88.88 \%)$. So it is tender and it cannot be used as pavement material and crushing.

Table 3 Micro-deval test

\begin{tabular}{llllll}
\hline $\begin{array}{l}\text { Granular } \\
\text { class }\end{array}$ & $\begin{array}{l}\text { Abrasive } \\
\text { charge } \\
\text { (G) }\end{array}$ & $\begin{array}{l}\text { Number } \\
\text { of turns }\end{array}$ & $\begin{array}{l}\text { Sample } \\
\text { mass } \\
(\mathbf{G})\end{array}$ & $\begin{array}{l}\text { Mass of } \\
\text { elements } \\
\text { less than } \\
\text { I.6mm } \\
(\mathbf{G})\end{array}$ & $\begin{array}{l}\text { MDE } \\
(\%)\end{array}$ \\
\hline $4-6.3$ & 450 & 12000 & 450 & 400 & 88.88
\end{tabular}




\section{Chemical analysis}

Figure 9 gives the composition of a sample of the limestone block of Djabel Estah made by atomic absorption spectrometry ${ }^{10}$ It is found that the limestone level does not exceed $60 \%$, which shows that this limestone is not pure and contains impurities. Indeed, this composition can present a great obstacle to better chemical use (such as chemical fertilizers and pharmaceuticals).

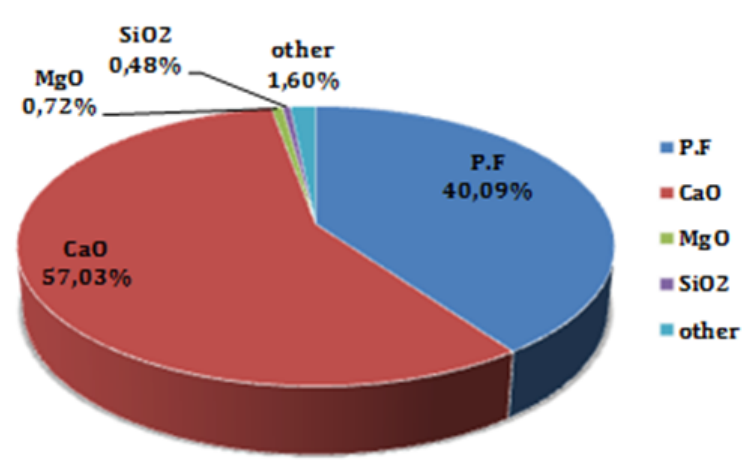

Figure 9 Chemical elements in the limestone block of Jbel Estah.

\section{$\mathrm{pH}$ meter}

$\mathrm{PH}$ is a coefficient that characterizes the acidity or the basicity of a soil. It defines the concentration of $\mathrm{H}+$ ions in the liquid phase of the soil. ${ }^{11}$ The determination of the $\mathrm{pH}$ was carried out on a mass sample equal to $20 \mathrm{~g}$ of the limestone of Jbel Estah. The test consists in placing the sample in $50 \mathrm{ml}$ of water on a magnetic stirrer with the presence of the magnetized bars for 5 minutes. After stirring, the mixture was allowed to stand for 10 minutes for decantation and the $\mathrm{pH}$-meter probe was immersed in the solution. The displayed value was 9.22 for a temperature of $14.1^{\circ} \mathrm{C}$. We note that the limestone of Jbel Estah is basic, which proves the absence of troublesome reactions with the cement.

\section{Conclusion}

The present paper has presented results of an experimental companion conducted on limestone blocks derived from Djabal Estah in the region of Gafsa at the southwestern of Tunisia. The following conclusions have been drawn from the investigation:

1. The limestone block of Jbel Estah has a very low resistance to wear and shock, for this it should not be used as roadway and crushing material.

2. The limestone block has a high water absorption coefficient (Ab $=15 \%$ ) which causes the risk of cracking of the mortars.
3. The limestone content $\mathrm{CaO}$ does not exceed $60 \%$, which shows that this limestone is not pure and contains impurities.

4. The limestone block will not have troublesome reactions with the cement since it is basic $(\mathrm{PH}=9.22)$ at a temperature of $14.1^{\circ} \mathbf{C}$.

Limestone blocks may be used for masonry, subject to special coatings.

\section{Acknowledgments}

The authors wish to thank the Civil Engineering Department of the Higher Institute of the Technological Studies (ISET) of Sfax for their assistance in the experimental tests.

\section{Conflicts of interest}

None.

\section{Funding}

None.

\section{References}

1. Office National des Mines ONM. Les potentialités en substances utiles $d u$ gouvernorat de Gafsa. 2010.

2. Sanders JE, Friedman GM Origin and occurrence of limestones. In Fairbridge Carbonate rocks. 169-266.

3. Bliss JD, Hayes TS, Orris GJ. USGS Limestone: A Crucial and Verstile Industrial Mineral Commodity. Republished from USGS fact sheet. 2008;2008-3089.

4. Westphal H. Limestone-mari alternations as environmental archives and the role of early diagenesis: Acritical review. International Journal of Earth Sciences. 2006;95(6):947-961.

5. NF EN 1097-6. Tests for Mecanical and Physical Properties of AggregatesPart6: Determination of Particle Density and Water Absorption. 2014.

6. NF EN 1097-1. Tests for mechanical and physical properties of aggregatesPart 1: Determination of the resistance to wear (micro-Deval); 2011.

7. Fornaciari G. Paleodiet research on Proto-Eneolithic skeletal remains of Piano Vento by atomic absorption spectrometry. In: Rivista di antropologia. 1990;68:129-140.

8. Welz B, Sperling M. Atomic Absorption Spectrometry. Wiley-VCH, Weinheim, Germany. 1999.

9. NF EN ISO 15586. Determination of trace elements using atomic absorption spectrometry with graphite furnace. 2003.

10. M Pinta M. Spectrométrie d'absorption atomique. Applications à l'analyse chimique Paris. 1980;pp.696.

11. RG Bates RG. Determination of pH: Theory and practice. John Wiley \& Sons. UK. 1973;77(9):737. 